\title{
Three-Dimensional Wave-Field Characteristics of Earth-Rock Dams with Different Hidden Hazards
}

\author{
Kui Wang $\mathbb{D}^{1}{ }^{1}{ }^{\text {Jie Liu, }}{ }^{2}$ Ying Zou, ${ }^{1,3}$ Mingjie Zhao, ${ }^{1}$ and Yue Qiang $\mathbb{D}^{1,4}$ \\ ${ }^{1}$ Key Laboratory of Hydraulic and Waterway Engineering of the Ministry of Education, Chongqing Jiaotong University, \\ Chongqing 400074, China \\ ${ }^{2}$ Chongqing Surveying and Design Institute of Water Resources, Electric Power and Architecture, Chongqing 400020, China \\ ${ }^{3}$ Hunan Technical College of Water Resources and Hydropower, Changsha 410131, China \\ ${ }^{4}$ Chongqing Three Gorges University, Chongqing 404100, China
}

Correspondence should be addressed to Kui Wang; anhuiwk@163.com

Received 24 May 2018; Accepted 31 October 2018; Published 9 December 2018

Guest Editor: Dan Ma

Copyright (c) 2018 Kui Wang et al. This is an open access article distributed under the Creative Commons Attribution License, which permits unrestricted use, distribution, and reproduction in any medium, provided the original work is properly cited.

The three-dimensional wave-field characteristics of dangerous earth-rock dams are the premise and foundation to identify the hidden hazards of the earth-rock dams via wave test method. Based on the equivalent elastic wave theory in isotropic mediums, the three-dimensional wave field of earth-rock dams with different defects was calculated using the finite element numerical simulation method. The characteristic and regularity of the three-dimensional wave field was explored. The result of the analysis shows that the size and position of the defects are closely related with the wave-field information received on the dam surface. The elasticity modulus and density of the defects have great effect on the wave field, and alternately, Poisson's ratio of the defects has little effect on the wave field. The greater the difference between the wave velocity of the hazardous materials and the dam body is, the stronger the energy of the scattered wave will be, which in turn will produce clearer lineups of the scattered wave on the timehistory profile. For a single wave movement signal, the dominant frequency amplitude is exponentially correlated with the longitudinal wave velocity of the hazardous materials. Therefore, in the process of wave detection for earth-rock dam hazards, the effect of the elasticity modulus, density, and wave velocity on the test signal should be taken into account. The dominant frequency amplitude can serve as one of the control parameters for interpretation of dam hazards by the analysis of the wave test signal.

\section{Introduction}

Geophysical exploration techniques is an important tool for studying the Earth's nonuniform structural and dynamic processes, and seismic tomography is one of the most widely used methods $[1,2]$. According to the wave field's characteristic parameters such as kinetic and kinematics, the range and position of any abnormalities can be obtained. The wave-field characteristics can be utilized for the inversion imaging of a particular medium or anomaly. Seismic wave detection technology has been widely used in geotechnical engineering applications, boasting fast, lossless, and simple operation [3-5]. Scholars have studied the application of seismic wave detection technology for earth-rock dams. This method was initially used for the geological exploration of the dam and then was gradually utilized for detection of the hidden hazards [6-8]. Research shows that although the wave signals on the dam surface contain abundant information of the dam's internal structure, it is difficult to improve its inversion accuracy using wave velocity parameters. Therefore, a key application of wave detection technology has become determining how to extract the information about hidden hazards from the test signal. It is necessary to analyze the wave-field distribution characteristics of the dam in order to effectively extract the information of the hidden hazard from the test signal.

The wave equation numerical simulation method is an effective means of studying the wave propagation law and analyzing the internal wave-field distribution of the structure. We can study the propagation mechanism of seismic waves and the interpretation of complex strata by simulating the wave propagation of the composite media. Therefore, 
more and more numerical simulation methods are used to study the propagation characteristics of seismic waves in structures. For example, Kim et al. implemented the finite element method to study the elastic wave propagation of a three-dimensional solid concrete model under the influence of cracks [9]. Narayan studied the propagation characteristics of Rayleigh waves in layered media by the finite difference method [10]. Bakamjian studied the simulation of the three-dimensional seismic wave propagation by the boundary integral equation method [11]. Du simulated the wave field of the anisotropic viscoelastic media via pseudospectrum method [12].

In summary, the interpretation method and wave-field characteristics of the existing nondestructive test data cannot directly serve as the basis for detecting the hidden dam's hazard. It is necessary to describe the wave-field characteristics of an earth-rock dam via wave detection technique.

\section{Three-Dimensional Wave-Field Analysis Model for Earth-Rock Dams}

Zhao et al. [8] have proposed a numerical simulation method for three-dimensional wave field of earth-rock dams. According to this method, a three-dimensional finite element model is established. The model size is shown in Figures 1 and 2, and the different hazardous materials have been considered in the model. First, the three-dimensional wave-field characteristics of earth-rock dams with/without hazards are compared, then, the effects of hidden hazards are analyzed. The parameters of the hazardous material are shown in Tables 1 and 2.

(1) Geometric division: theoretically, the wave phenomenon can be observed in a finite element model, so the unit grid size should be less than the wavelength. Usually, the unit grid size is selected less than half of a wavelength to increase accuracy [7]. The unit grid density can be increased depending on the actual model size to improve the accuracy. The data collection interval is the step length of the finite element analysis. In principle, the time step should set to a value where the wave cannot pass through the unit.

In this paper, tetrahedron unit SOLID92 with 10 nodes is selected. The grid can be divided freely. The grid size of the dam mass is $4 \mathrm{~m}$, and the grid size of the hazardous mass is $2 \mathrm{~m}$. The analysis time $T=0.8 \mathrm{~s}$, and the time step $\Delta t=1 \mathrm{~ms}$.

(2) Boundary conditions: based on the viscoelastic boundary conditions in ANSYS software, a spring damper is utilized to mitigate the effects of boundary-reflected waves on the wave-field analysis.

(3) Centrum: the centrum is excited by a delta impulse function. Its expression is

$$
\vec{F}(t)= \begin{cases}\vec{A} \cdot 2 f \cdot t, & 0 \leq t \leq t_{0} \\ \vec{A} \cdot 2 f \cdot t_{0}+\vec{A} \cdot 2 f \cdot\left(t-t_{0}\right), & t_{0} \leq t \leq T\end{cases}
$$

where $A$ is the maximum amplitude of the excitation force. $f$ is the dominant frequency of the wave load function, where the dominant frequency magnitude directly represents the width of the frequency band. $t_{0}$ is the main peak time of the wave load, and $T$ is the centrum cycle.

In this paper, $\vec{A}=-20 \mathrm{kN}$ (vertical downward direction), $f=25 \mathrm{~Hz}, t_{0}=0.02 \mathrm{~s}$, and $T=0.04 \mathrm{~s}$.

\section{Three-Dimensional Wave-Field Characteristics of Earth-Rock Dams with/ without Hazards}

Wave propagation can be directly judged on the basis of the displacement field. Thus, the displacement field is used to analyze the characteristic rules of the wave field. The threedimensional wave-field characteristics obtained from numerical simulation are shown in Figure 3.

By analyzing Figure 3, it is clear that a direct wave can produce scattered waves when it interacts with a hazardous mass different from the dam material. The scattered wave spreads from the hazardous site to the surface of the dam mass over time exhibiting significant motion. The direct wave gradually spreads out to the distance until eventual absorption caused by the action of the viscous-elastic boundary. At this point, the vibration of the dam particle becomes smooth.

The time-history curves are collected at various measuring points parallel to the dam axis on the dam crest. Figure 4 shows the time-history profile that reflects the overall wave-field characteristics.

Based on a contrastive analysis of the time-history profile (Figure 4), it is thus clear that the wave-field information of the earth-rock dam spreads out in the periphery in a very regular manner, and there is no other wave information after the direct wave over time when there is no hazardous mass. When a hazardous mass is present, a scattered wave is produced which spreads to the dam crest once the direct wave reaches the hazardous mass. Therefore, significant wave motion signals occur again on the time-history profile in the period following the passage of the direct wave, and these signals are the scattered waves arising due to the presence of the hazardous mass. Figure 3 (wave field) and Figure 4 (time-history profile) indicate that the scattered wave spreads to the dam crest along the surface of the dam slope and leads to significant phase changes in wave motion. The figures show that the $X$ direction has more significant characteristics than the other two directions. Thus, the existence and characteristics of the hazardous mass within the dam mass can be judged depending on the scattered wave signals received by the surface of the dam.

\section{Analysis and Discussion for the Effects of Hidden Hazards}

4.1. Impact Analysis for Elasticity Modulus and Density. Wave velocity is a basic wave parameter for measuring material properties, and it can be used to measure the 


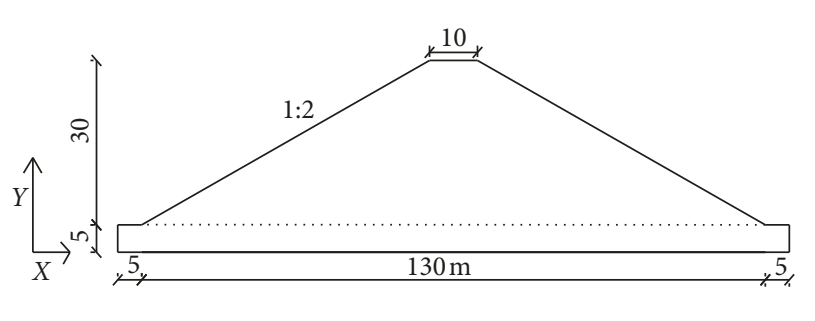

(a)

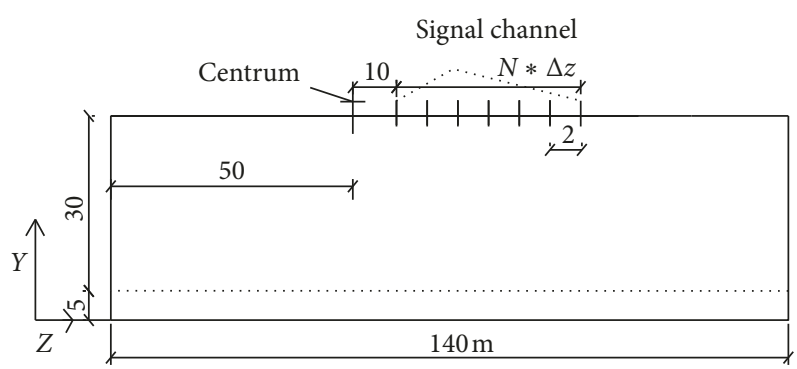

(b)

Figure 1: Schematic diagram for size of the finite element model of a hazard-free earth-rock dam. (a) Transverse section. (b) Longitudinal section.

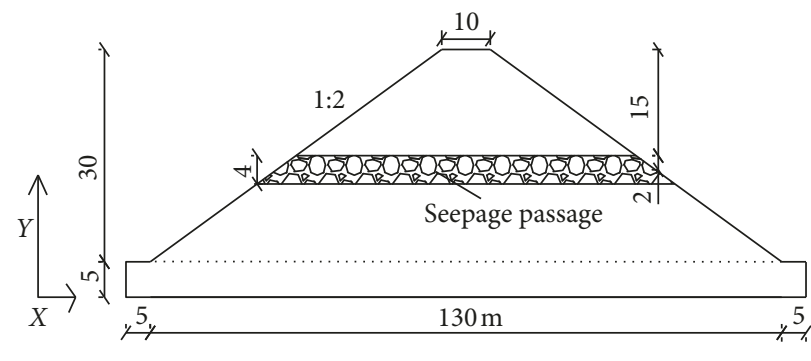

(a)

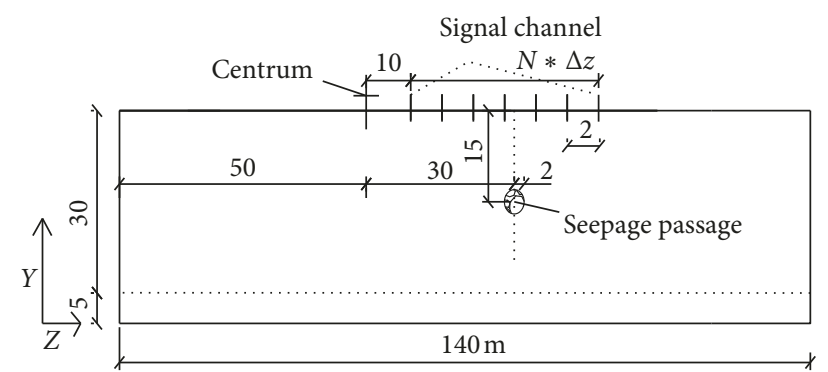

(b)

FIgURE 2: Schematic diagram for size of the finite element model of earth-rock dam with leakage passages. (a) Transverse section. (b) Longitudinal section.

TABLe 1: Material parameters for three-dimensional finite element models.

\begin{tabular}{|c|c|c|c|c|c|c|}
\hline Material no. & Species & $\begin{array}{c}\text { Density } \rho \\
\left(\mathrm{kg} / \mathrm{m}^{3}\right)\end{array}$ & $\begin{array}{c}\text { Elasticity modulus } \\
E\left(P_{a}\right)\end{array}$ & $\begin{array}{c}\text { Poisson's } \\
\text { ratio }(\mu)\end{array}$ & $\begin{array}{l}\text { Longitudinal wave } \\
\text { velocity } V_{p}(\mathrm{~m} / \mathrm{s})\end{array}$ & $\begin{array}{l}\text { Transverse wave } \\
\text { velocity } V_{s}(\mathrm{~m} / \mathrm{s})\end{array}$ \\
\hline 0 & Dam body & 2200 & $5.16 E 8$ & 0.3 & 560 & 300.00 \\
\hline 1 & & 500 & $3.71 E 4$ & 0.3 & 10 & 5.35 \\
\hline 2 & & 800 & $5.90 E 6$ & 0.3 & 100 & 53.45 \\
\hline 3 & & 1100 & $3.27 E 7$ & 0.3 & 200 & 106.90 \\
\hline 4 & Hazards & 1400 & $9.36 E 7$ & 0.3 & 300 & 160.35 \\
\hline 5 & & 1700 & $2.02 E 8$ & 0.3 & 400 & 213.81 \\
\hline 6 & & 2000 & $3.71 E 8$ & 0.3 & 500 & 267.26 \\
\hline 7 & & 2400 & $6.42 E 8$ & 0.3 & 600 & 320.71 \\
\hline
\end{tabular}

TABLe 2: Material parameters for defects corresponding to different Poisson's ratios.

\begin{tabular}{|c|c|c|c|c|c|}
\hline Material no. & $\begin{array}{c}\text { Density } \rho \\
\left(\mathrm{kg} / \mathrm{m}^{3}\right)\end{array}$ & $\begin{array}{c}\text { Elasticity modulus } \\
E\left(P_{a}\right)\end{array}$ & $\begin{array}{l}\text { Poisson's } \\
\text { ratio }(\mu)\end{array}$ & $\begin{array}{l}\text { Longitudinal wave } \\
\text { velocity } V_{p}(\mathrm{~m} / \mathrm{s})\end{array}$ & $\begin{array}{l}\text { Transverse wave } \\
\text { velocity } V_{s}(\mathrm{~m} / \mathrm{s})\end{array}$ \\
\hline 0 & 2200 & $5.16 E 8$ & 0.30 & 560.00 & 300.00 \\
\hline 1 & 2200 & $5.16 E 8$ & 0 & 484.30 & 342.45 \\
\hline 2 & 2200 & $5.16 E 8$ & 0.1 & 489.77 & 326.51 \\
\hline 3 & 2200 & $5.16 E 8$ & 0.20 & 510.50 & 312.61 \\
\hline 4 & 2200 & $5.16 E 8$ & 0.35 & 613.54 & 294.74 \\
\hline 5 & 2200 & $5.16 E 8$ & 0.40 & 708.94 & 289.42 \\
\hline 6 & 2200 & $5.16 E 8$ & 0.45 & 943.21 & 284.39 \\
\hline
\end{tabular}

material properties of the hazardous mass. In cases with a fixed Poisson's ratio, we discuss the effects of the elasticity modulus and density on the wave-field characteristics. The model is designed in the same manner as mentioned earlier. The hazard size is $R=4 \mathrm{~m}$. The distance between the central position and dam crest is $h=9 \mathrm{~m}$. The parameters of the hazardous material are shown in Table 1. 


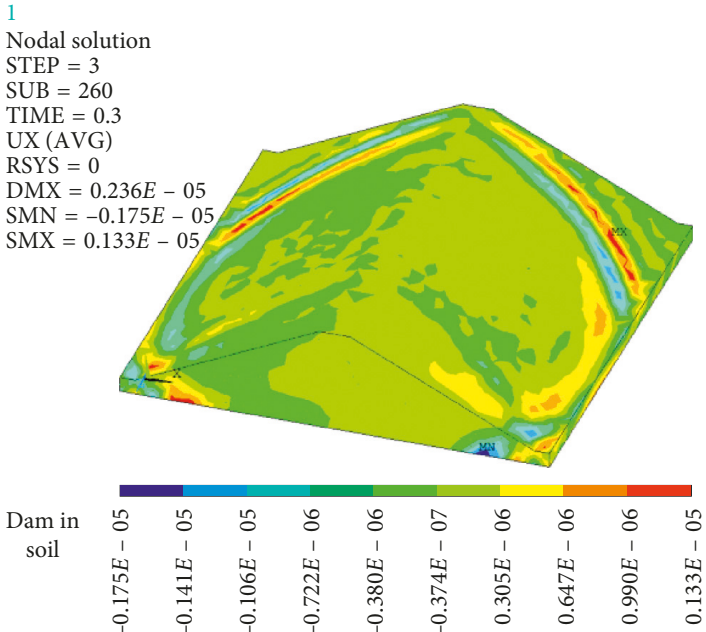

(a)

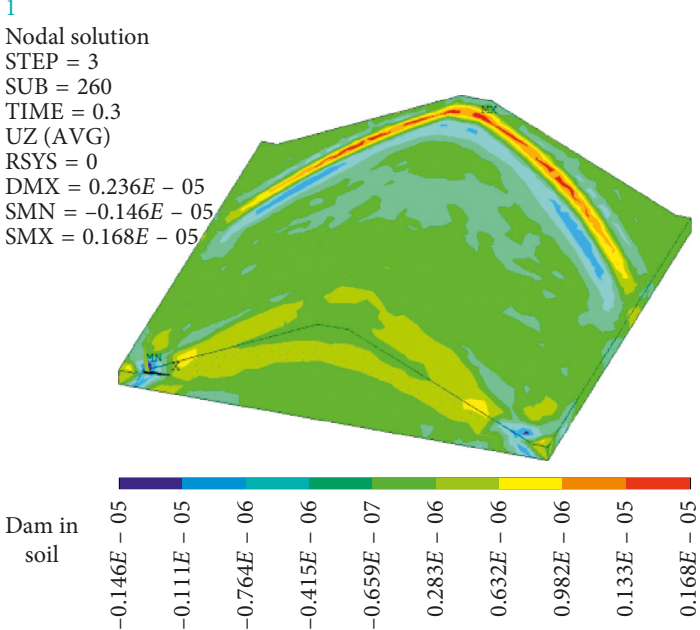

(c)

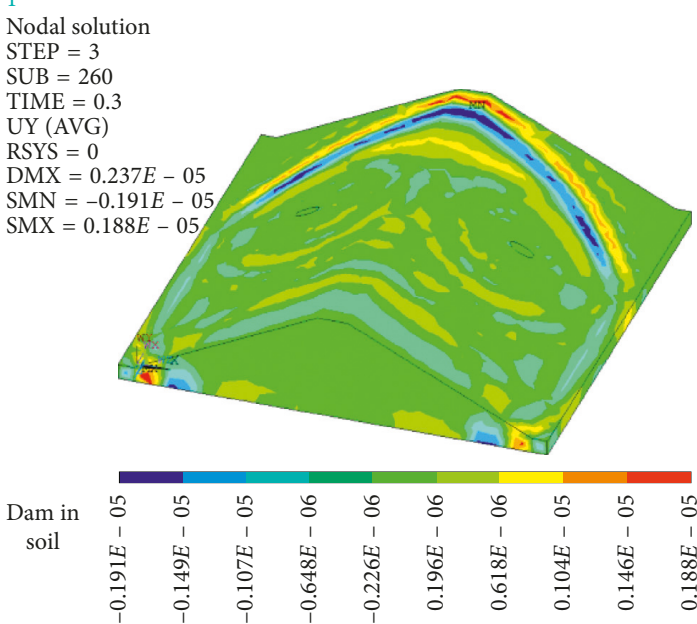

(e)
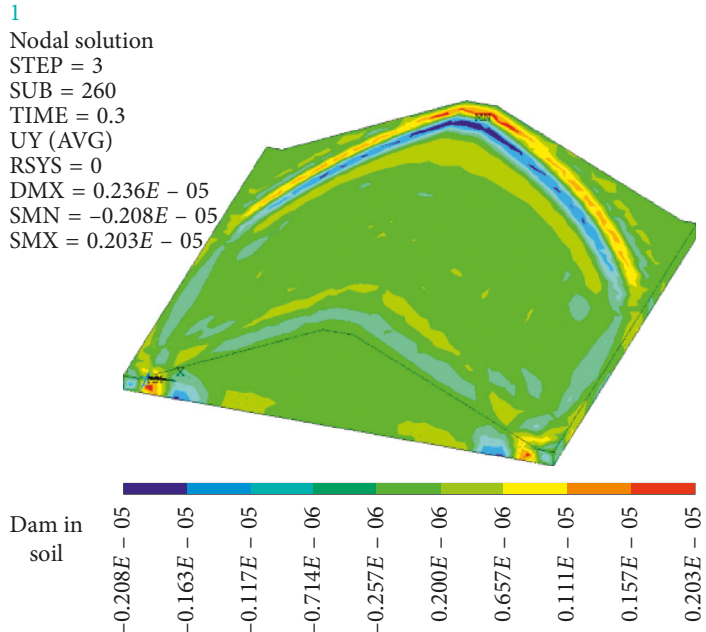

(b)

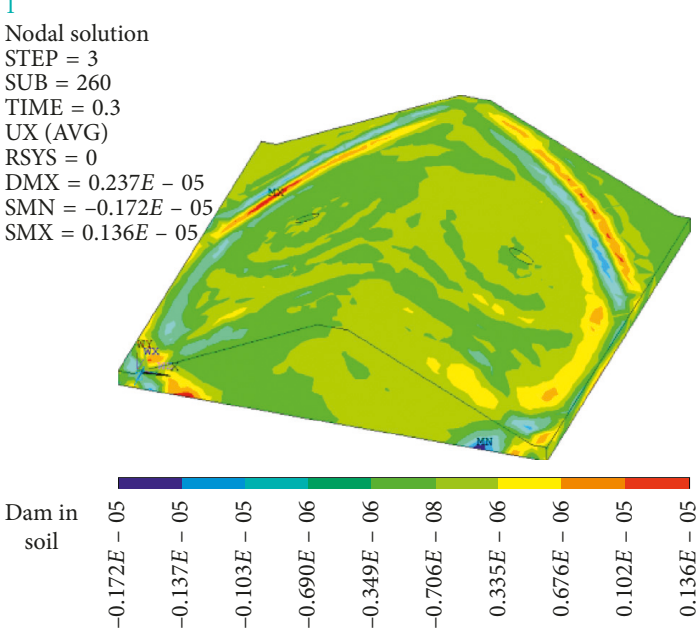

(d)

Nodal solution

$\mathrm{STEP}=3$

$\mathrm{SUB}=260$

TIME $=0.3$

UZ (AVG)

RSYS $=0$

$\mathrm{DMX}=0.237 E-05$

SMN $=-0.123 E-05$

$\mathrm{SMX}=0.165 E-05$

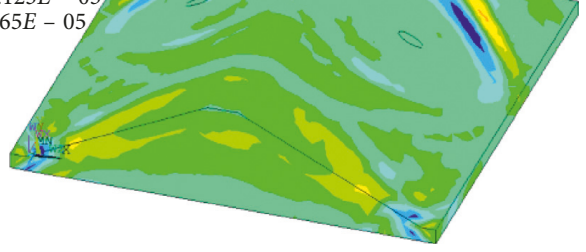

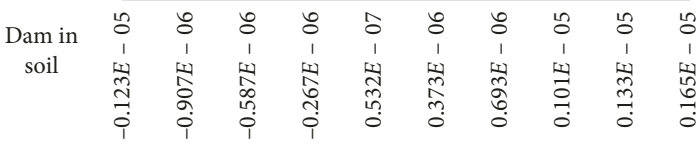

(f)

Figure 3: Three-dimensional wave field of the earth-rock dams with/without hidden hazards. (a) Displacement in $x$ direction at $0.3 \mathrm{~s}$ in a case with no hazards. (b) Displacement in $y$ direction at $0.3 \mathrm{~s}$ in a case with no hazards. (c) Displacement in $z$ direction at $0.3 \mathrm{~s}$ in a case with no hazards. (d) Displacement in $x$ direction at $0.3 \mathrm{~s}$ in a case with hazards. (e) Displacement in $y$ direction at $0.3 \mathrm{~s}$ in a case with hazards. (f) Displacement in $z$ direction at $0.3 \mathrm{~s}$ in a case with hazards. 


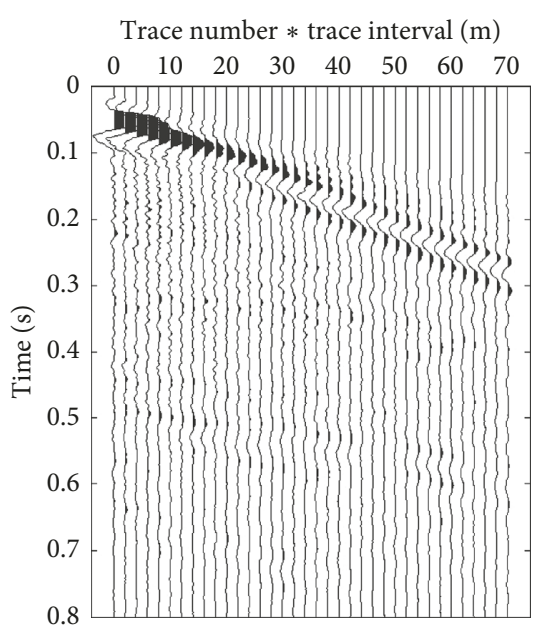

(a)

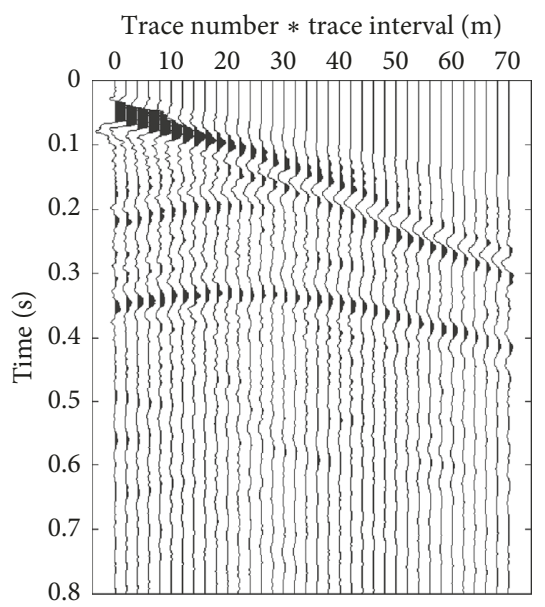

(d)

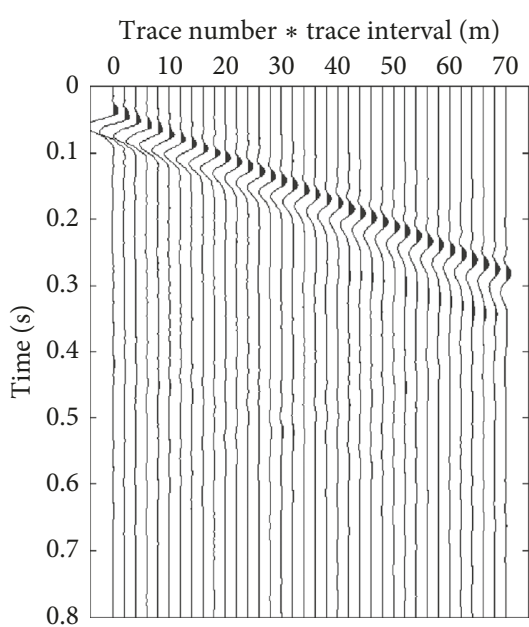

(b)

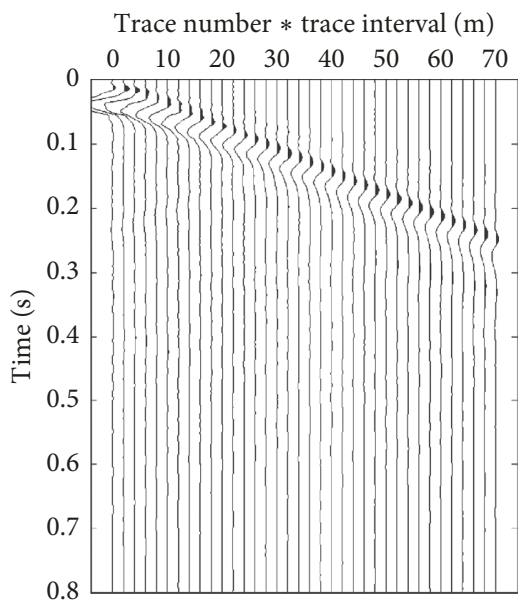

(e)

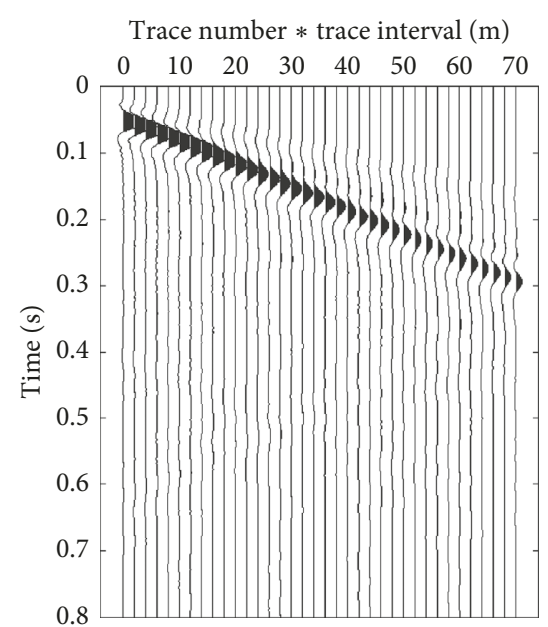

(c)

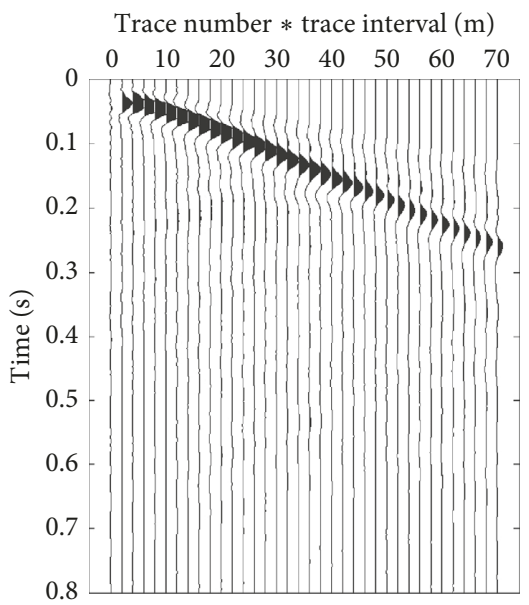

(f)

FIGURE 4: Time-history profile of the earth-rock dams with/without hidden hazards at the same measuring line. (a) Displacement in $x$ direction in a case with no hazards. (b) Displacement in $y$ direction in a case with no hazards. (c) Displacement in $z$ direction in a case with no hazards. (d) Displacement in $x$ direction in a case with hazards. (e) Displacement in $y$ direction in a case with hazards. (f) Displacement in $z$ direction in a case with hazards.

\subsection{Characteristic Analysis for the Time-History Profile.} The time-history curve for all measuring points is used to establish a profile to analyze the full wave-field characteristics (Figure 5).

The first phase of the scattering signal received in the $X$ direction is between $0.1 \mathrm{~s}$ and $0.18 \mathrm{~s}$ and the central position in the vicinity of the 8 th-10th scattering phase. The second phase of the scattering signal received in the $X$ direction is between $0.17 \mathrm{~s}$ and $0.24 \mathrm{~s}$ and the central position in the vicinity of the 8 th-10th scattering phase. It can be concluded that the time points at which the scattered wave generated by the hazardous mass in the same position received on the same measuring line of the dam crest are basically the same. However, the closer the proximity of the defects to that of the surrounding media, the less significant the scattering result. There is limited information available regarding the lineups for $Y$ direction and $Z$ direction. The time points for all lineups are basically the same. A greater difference in material parameters presents a clearer lineup.
4.3. Characteristic Analysis for Wave Signals. Time domain analysis: to enrich the analysis results, the time-history data of a single measuring point is subjected to a quantitative contrastive analysis based on the analysis for the full wave field. The time-history curve for the same measuring point on the measuring line is selected for comparison (Figure 6, No. 14 measuring point is selected). A single wave signal on the dam surface in the case of different hazard characteristics has the following regularities: the vibration amplitude of single measuring points at the same distance from the centrum decreases with the decreased difference in material properties between the defects and the surrounding media. Therefore, the wave amplitude with an initiation point of scattered signals serves as a parameter for judging the material properties of the defects.

Frequency domain analysis: a time-frequency analysis is conducted for the time-history data of No. 8 measuring point in different models mentioned above. Accordingly, we can obtain the regularity concerning the effect of 


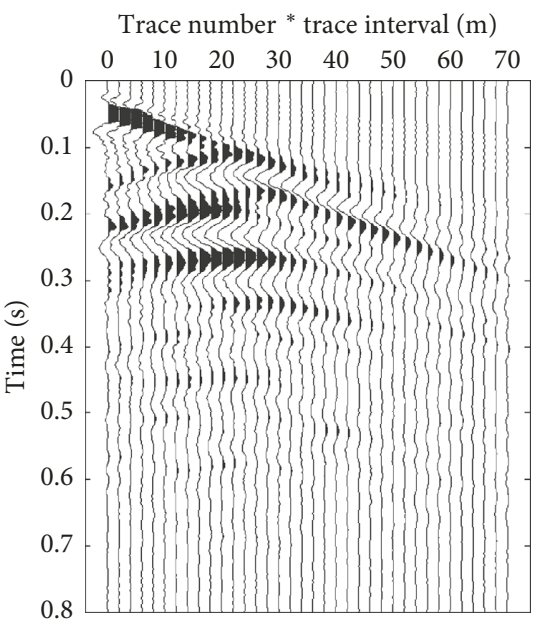

(a)

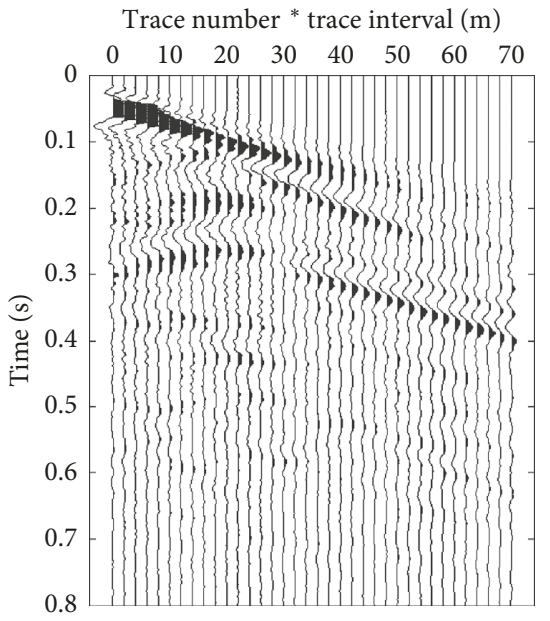

(d)

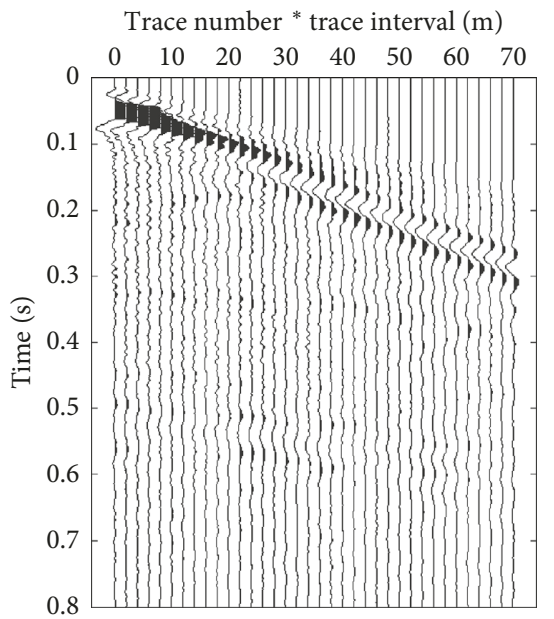

(g)

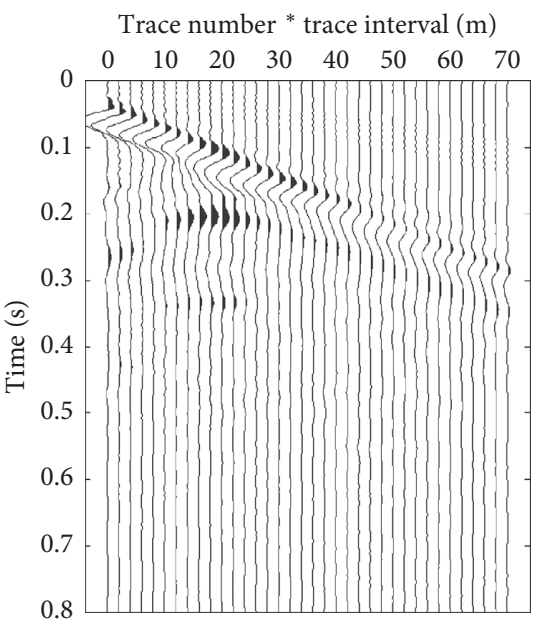

(b)

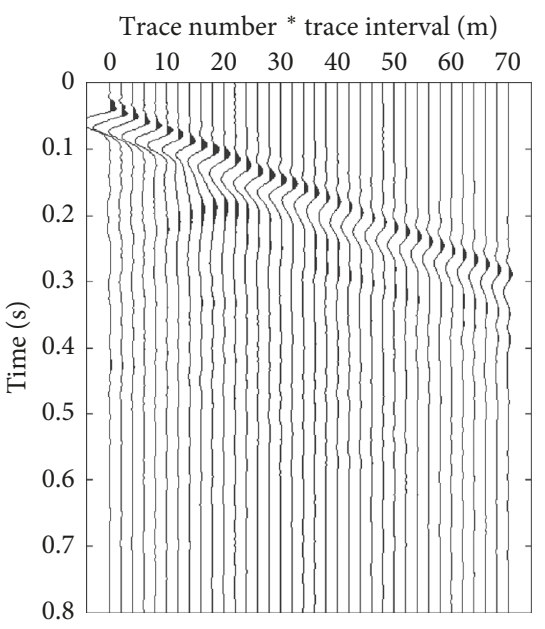

(e)

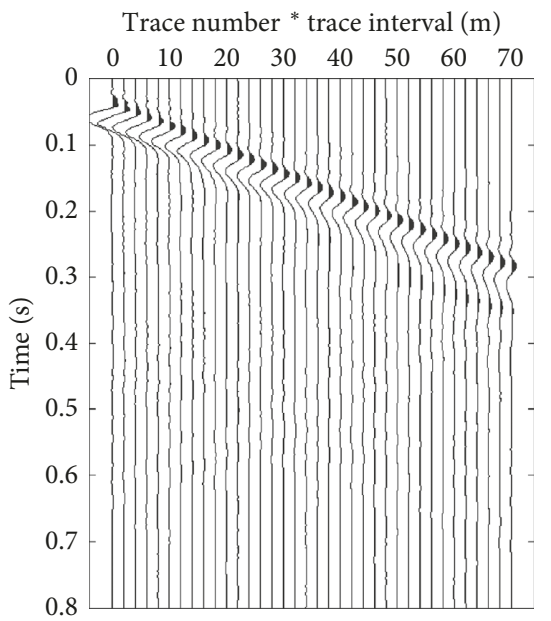

(h)

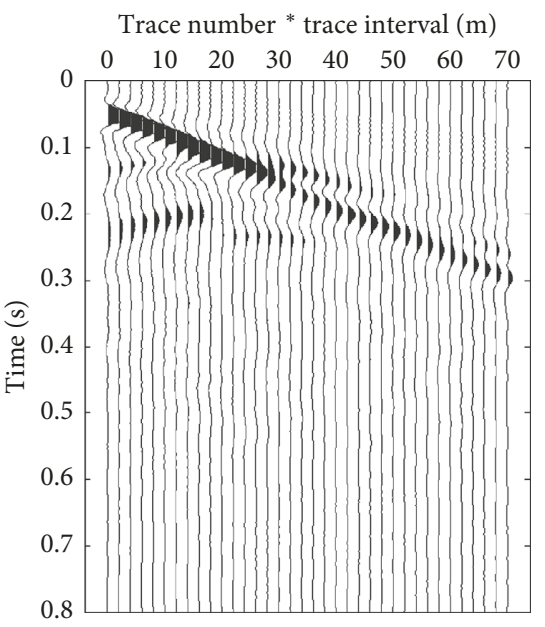

(c)

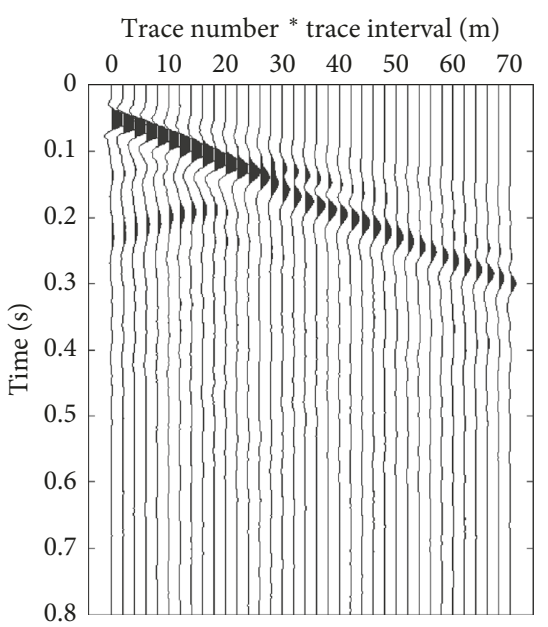

(f)

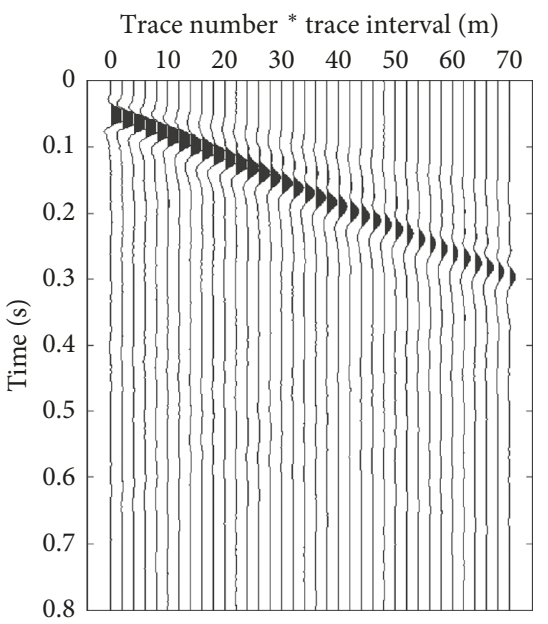

(i)

FIgURE 5: Time-history profile for measuring lines of earth-rock dam crests with different hazard characteristics. (a) Time-history profile for No. 1 material displacement in $X$ direction. (b) Time-history profile for No. 1 material displacement in $Y$ direction. (c) Time-history profile for No. 1 material displacement in $Z$ direction. (d) Time-history profile for No. 4 material displacement in $X$ direction. (e) Time-history profile for No. 4 material displacement in $Y$ direction. (f) Time-history profile for No. 4 material displacement in $Z$ direction. (g) Timehistory profile for No. 6 material displacement in $X$ direction. (h) Time-history profile for No. 6 material displacement in $Y$ direction. (i) Time-history profile for No. 6 material displacement in $Z$ direction. 


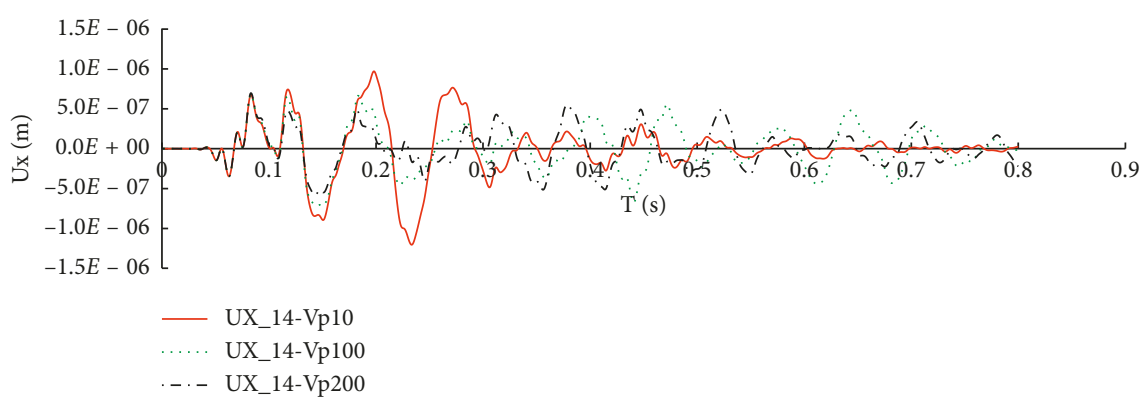

(a)

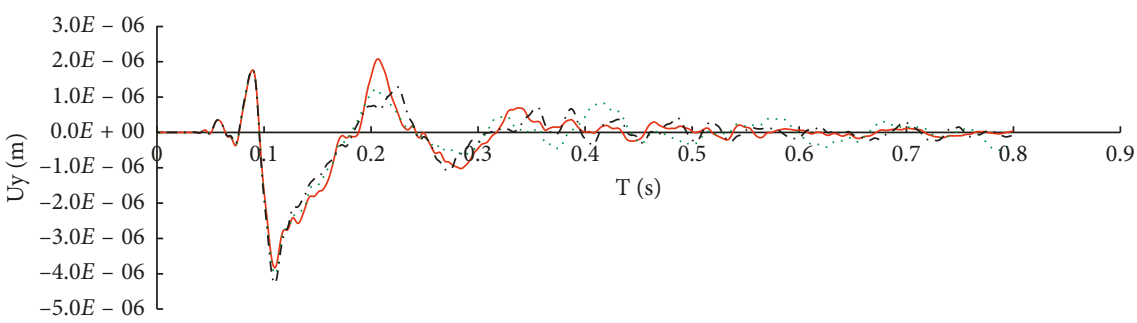

$$
\begin{array}{ll}
\text { - UY_14-Vp10 } & \text { UY } \\
\text {..... } & \text { UY_14-Vp100 } \\
\text {-.- } & \text { UY_14-Vp200 }
\end{array}
$$

(b)

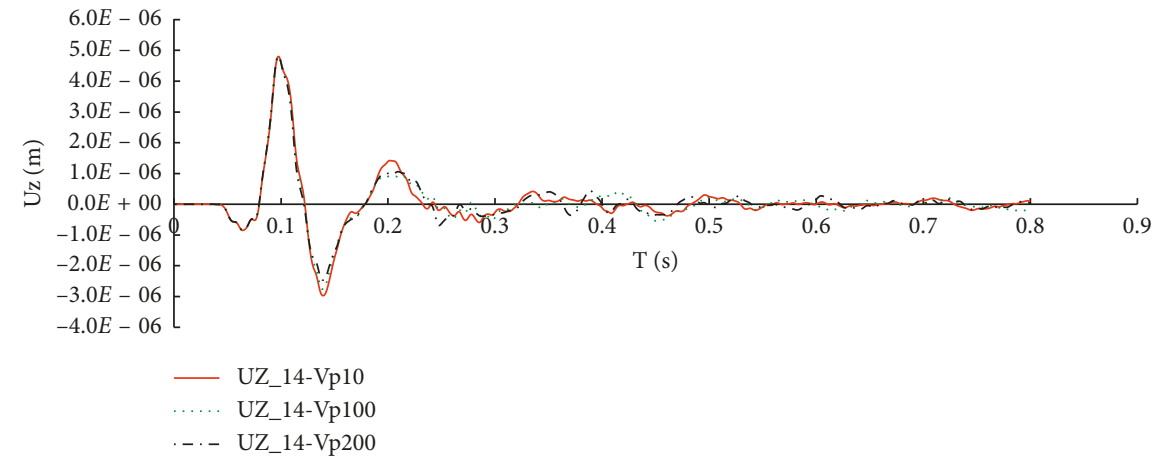

(c)

Figure 6: Time-history curve for displacement of No. 8 measuring point of earth-rock dam with different hazard characteristics. (a) $X$ direction. (b) $Y$ direction. (c) $Z$ direction.

characteristics of the hazardous material on the wave-field characteristics in the frequency domain (Figure 7).

As the dam and hazard materials exhibit decreasing differences in wave parameters, the dominant frequency amplitude of the wave signal decreases significantly, and the regularities in three directions stay consistent. Obviously, the dominant frequency amplitude is highly sensitive in the wave field. Therefore, it can serve as an important parameter in an inversion study in the actual detection of wave motion, and the expected degree of damage can be estimated on the basis of the dominant frequency amplitude of the wave signal of a single measuring point in the site investigation.

4.4. Impact Analysis for Poisson's Ratio. Based on the nature of homogeneous media, Poisson's ratio is another parameter determining the elastic characteristics of a material. Therefore, it is necessary to study the effect of Poisson's ratio on the wave-field information. The elasticity modulus and density of the hazardous material remain unchanged. The specific material parameters are shown in Table 2. The model size and design are the same as mentioned above.

The time-history curves for all measuring points on the same measuring line are generated by changing Poisson's ratio of the hazardous material. The analysis of the wave field of the hazardous earth-rock dam shows that the wave field in the $X$ direction is highly sensitive to changes in hazards. Therefore, the time-history profiles for wave motions in the $X$ direction are shown in Figure 8.

Figure 8 shows that the characteristic of the scattered wave is not significant by changing Poisson's ratio alone, and there are no significant changes in phase that can be observed in the time-history profile. A weak scattering result can still be observed when the elasticity modulus and density are changed and the wave velocity of the longitudinal wave reaches approximately $500 \mathrm{~m} / \mathrm{s}$. No scattering result can be observed 


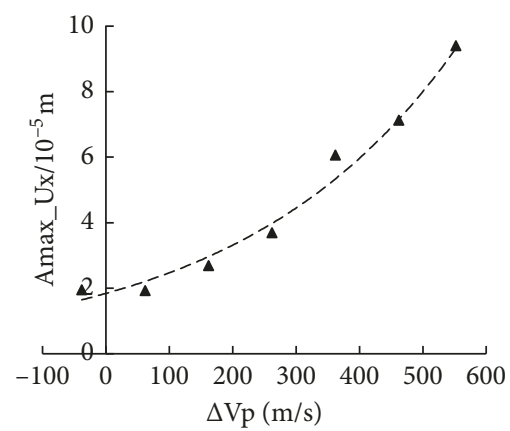

(a)

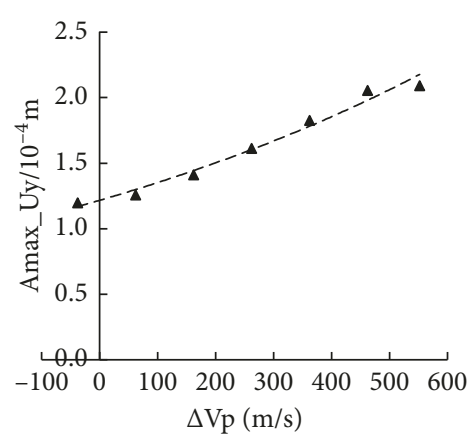

(b)

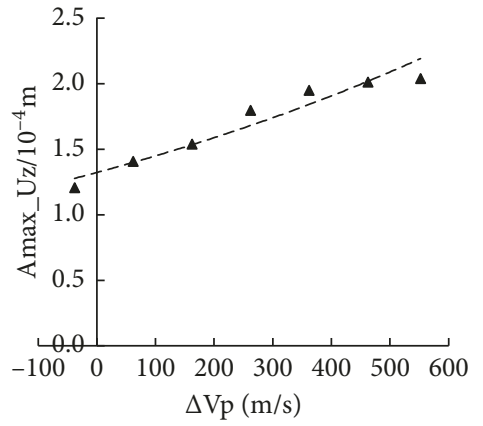

(c)

Figure 7: Spectral value of No. 8 measuring point of earth-rock dam with different hazard characteristics. (a) Spectral value corresponding to the dominant frequency of the vibration signal in the $X$ direction. (b) Spectral value corresponding to the dominant frequency of the vibration signal in the $Y$ direction. (c) Spectral value corresponding to the dominant frequency of the vibration signal in the $Z$ direction.

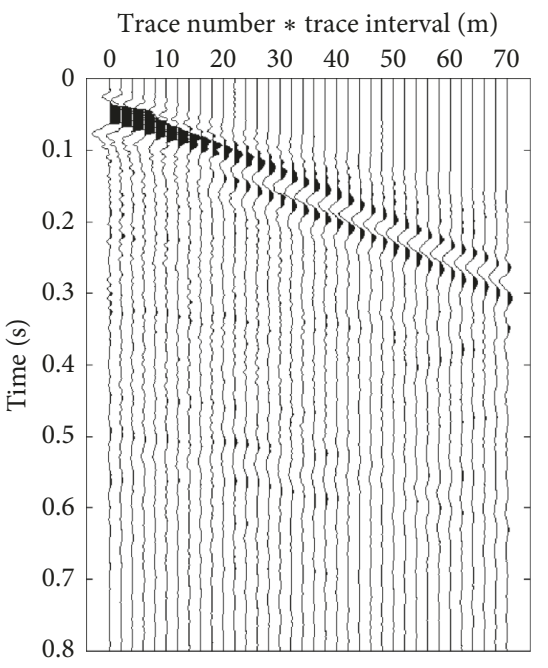

(a)

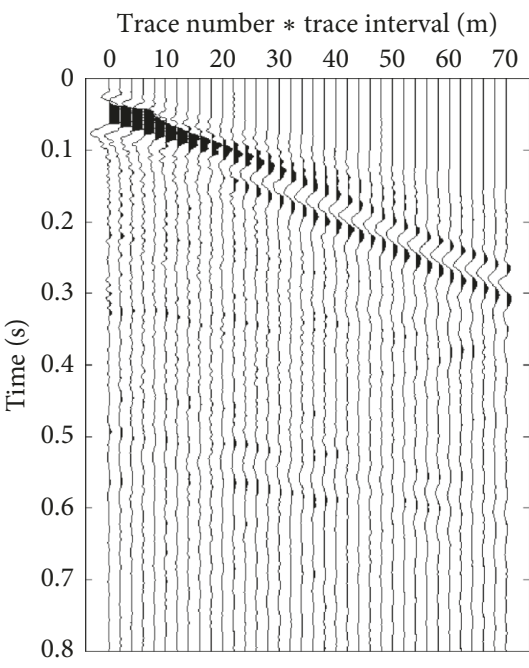

(b)

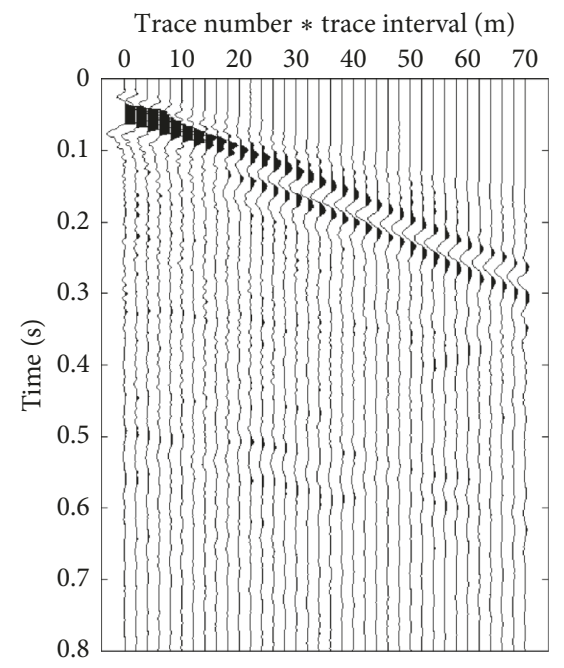

(c)

Figure 8: Time-history profile corresponding to Ux measuring line of the earth-rock dam crest with different hazard Poisson's ratios. (a) $\mu=$ 0. (b) $\mu=0.1$. (c) $\mu=0.45$.

when only Poisson's ratio is changed and the wave velocity of the longitudinal wave is $484.3 \mathrm{~m} / \mathrm{s}$. Therefore, we conclude that Poisson's ratio of the defects has little effect on the scattered wave field of the earth-rock dam. In other words, the scattered wave field is not too sensitive to the changes in Poisson's ratio of the hazardous material.

The time-history curve for the same measuring point on the measuring line is selected for comparison (Figure 9). With increasing difference in wave velocity between the defect material and the dam mass material, the wave motion increases slightly. However, there is no significantly abnormal wave motion in the later stage. We conclude that Poisson's ratio has little effect on the wave field of the threedimensional earth-rock dam.

\section{Conclusion and Suggestions}

A finite element model for the analysis of the threedimensional wave field of the earth-rock dam with defects was established for numerical simulation of a wave field. The wave-field characteristics of the earth-rock dam with/without defects were analyzed. We concluded the following:

(1) When hazards are present in the earth-rock dam and the size of the defects are not significant enough to cause diffraction, it will produce a series of scattering phenomena, such as reflection and refraction, when the direct wave meets the defect. The scattered wave spreads out and reaches the surface of the dam mass and then is finally received by the detector. It indicates a significant wave-field disturbance. The time-history curve still fluctuates after the direct wave is propagated. The lineups of the scattered wave are present in the time-history profile reflecting the overall wave field. The lineups are an important signal that reflects the characteristics of the scattered wave field. It can be used for judging the presence or absence of hazards. 


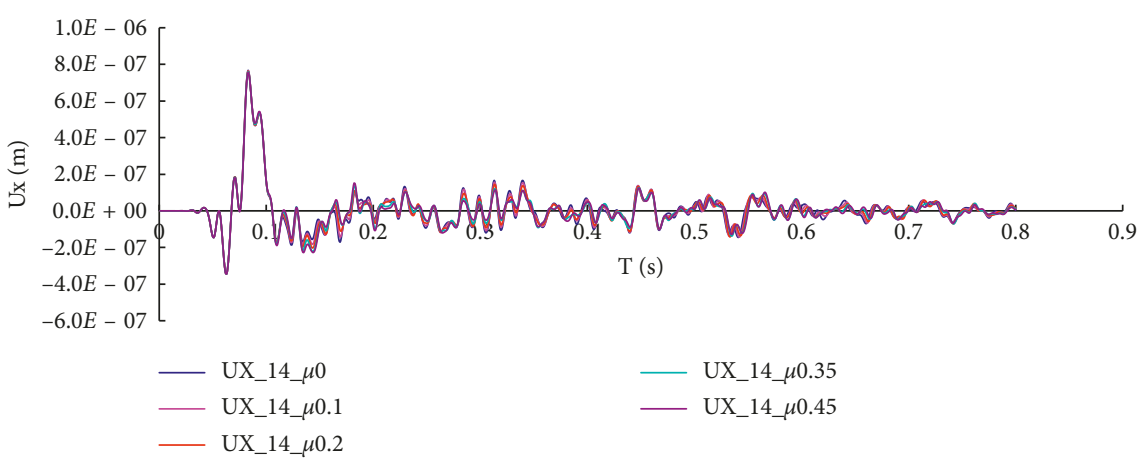

(a)

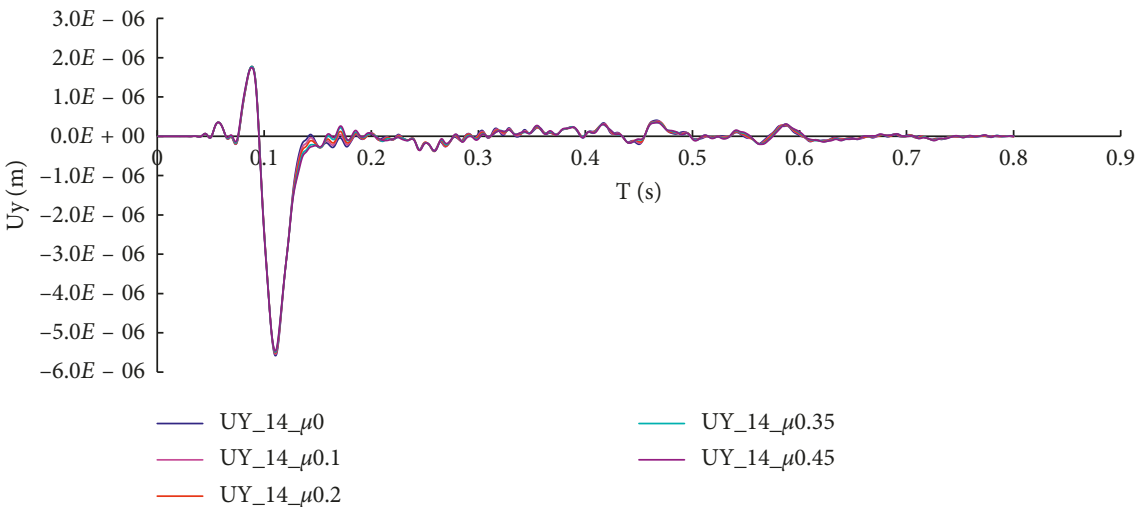

(b)

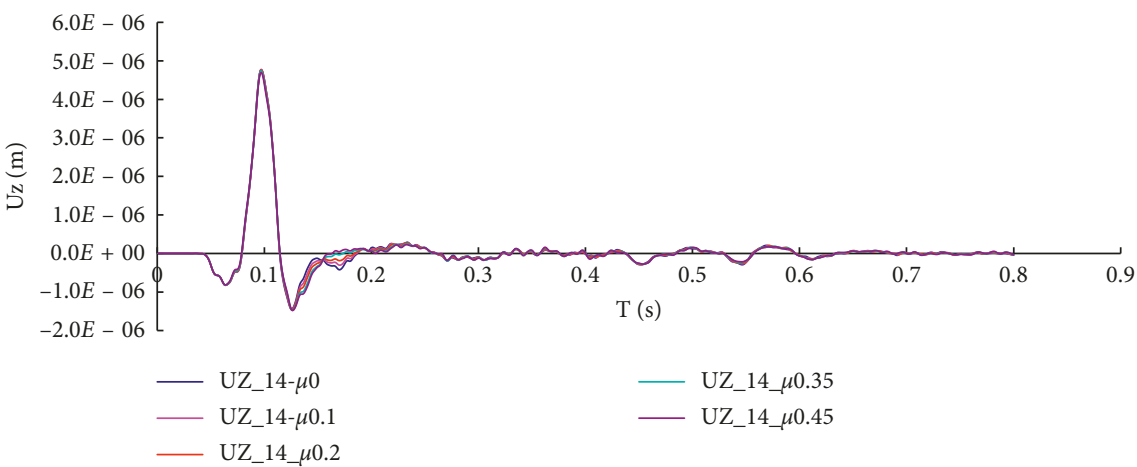

(c)

Figure 9: Time-history curve for displacement of No. 8 measuring point on the measuring line of defects in the case of different Poisson's ratios. (a) $X$ direction. (b) $Y$ direction. (c) $Z$ direction.

(2) The result of the finite element value calculation in the wave-field analysis shows that the vertical triangular load excitation method will be used in the wave motion model of earth-rock dam. The threedimensional wave field of a through leakage passage is highly sensitive to abnormal wave motions in the direction vertical to the dam's axis.

(3) The result of the numerical calculation of the finite element model of the earth-rock dam with different hazardous material characteristics shows that a greater difference in wave velocity between the defect's material and the dam's material indicates a more intensive scattered wave field and a clearer scattering axis on the time-history profile. In terms of a single wave motion signal, the amplitude corresponding to the dominant frequency is exponentially correlated with the longitudinal wave velocity of the hazardous material. Therefore, the amplitude corresponding to the dominant frequency in the inverse analysis for wave motion can serve as one of the control parameters for inversion.

(4) When the differences in longitudinal wave velocity are the same between hazardous materials of the hazardous earth-rock dam, the elasticity modulus and density of hazardous material have a significant effect on the wave field. They are highly sensitive in the wave motion analysis; Poisson's ratio is less sensitive in the wave motion analysis. It is very 
difficult to distinguish between defects with different Poisson's ratios during the process of actual exploration.

\section{Data Availability}

All the data in this paper were obtained by numerical simulation, and the numerical simulation software is ANYS. The software was purchased by Chongqing Jiaotong University.

\section{Conflicts of Interest}

The authors declare that they have no conflicts of interest.

\section{Acknowledgments}

The authors gratefully acknowledge the financial supports from the Natural Science Foundation Project of China (Grant nos. 51609027 and 51879017), Chongqing Research Program of Basic Research and Frontier Technology (Grant nos. cstc2016jcyjA0016 and cstc2017jcyjBX0066), and Scientific and Technological Research Program of Chongqing Municipal Education Commission (Grant no. KJ1501007).

\section{References}

[1] D. Ma, X. Cai, Q. Li, and H. Duan, "In-situ and numerical investigation of groundwater inrush hazard from grouted karst collapse pillar in longwall mining," Water (Switzerland), vol. 10, no. 9, p. 1187, 2018.

[2] L. De Giorgi and G. Leucci, "Detection of hazardous cavities below a road using combined geophysical methods," Surveys in Geophysics, vol. 35, no. 4, pp. 1003-1021, 2014.

[3] H. A. Hamdan and A. Vafidis, "Joint inversion of 2D resistivity and seismic travel time data to image saltwater intrusion over karstic areas," Environmental Earth Sciences, vol. 68, no. 7, pp. 1877-1885, 2013.

[4] A. M. E. Mohamed, A. S. A. Abu El Ata, F. Abdel Azim et al., "Site-specific shear wave velocity investigation for geotechnical engineering applications using seismic refraction and 2D multi-channel analysis of surface waves," NRIAG Journal of Astronomy and Geophysics, vol. 2, no. 1, pp. 88-101, 2013.

[5] J. M. Crane, J. M. Lorenzo, and J. B. Harris, "A new electrical and mechanically detonatable shear wave source for near surface $(0-30 \mathrm{~m})$ seismic acquisition," Journal of Applied Geophysics, vol. 91, pp. 1-8, 2013.

[6] S.-Z. Wang, C. Tan, G. Chen et al., "The application of Rayleigh-wave exploration on detecting hidden dam troubles," Progress in Geophysics, vol. 20, no. 1, pp. 262-266, 2005.

[7] M.-Jie Zhao, Y. U. Dong, and H.-Yan Zhao, "Experimental study on velocity and resistivity combined tomography for diagnosing leakage in earth rock-fill dam," Journal of $\mathrm{Hy}$ draulic Engineering, vol. 43, no. 1, pp. 118-126, 2012.

[8] M.-J. Zhao, Y. Zou, and X. Zhang, "Three-dimensional numerical simulation and characteristic analysis of wavefield for earth-rock dam contain hidden troubles," Journal of $\mathrm{Hy}$ draulic Engineering, vol. 47, no. 5, pp. 599-607, 2016.

[9] J. Kim, J. Woo, and W. B. Na, "Finite element simulation of two-point elastic wave excitation method for damage detection in concrete structures," Russian Journal of Nondestructive Testing, vol. 44, no. 10, pp. 719-726, 2008.
[10] J. P. , S. K. Narayan, "Study of effects of focal depth on the characteristics of Rayleigh waves using finite difference method," Acta Geophysica, vol. 58, no. 4, pp. 624-644, 2010.

[11] B. Bakamjian, Boundary Integrals: An Efficient Method for Modeling Seismic Wave Propagation in 3-D, University of Tulsa, Tulsa, Oklahoma, 1992.

[12] Q.-Z. Du, "Wavefield forward modelling with the pseudospectral method in viscoelastic and azimuthally anisotropic media," ACTA Physica Sinica, vol. 53, no. 12, pp. 4428-4434, 2004. 


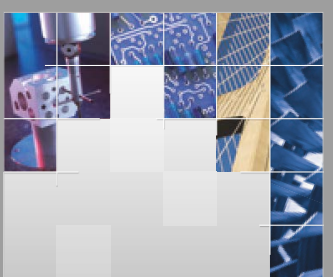

\section{Enfincering}
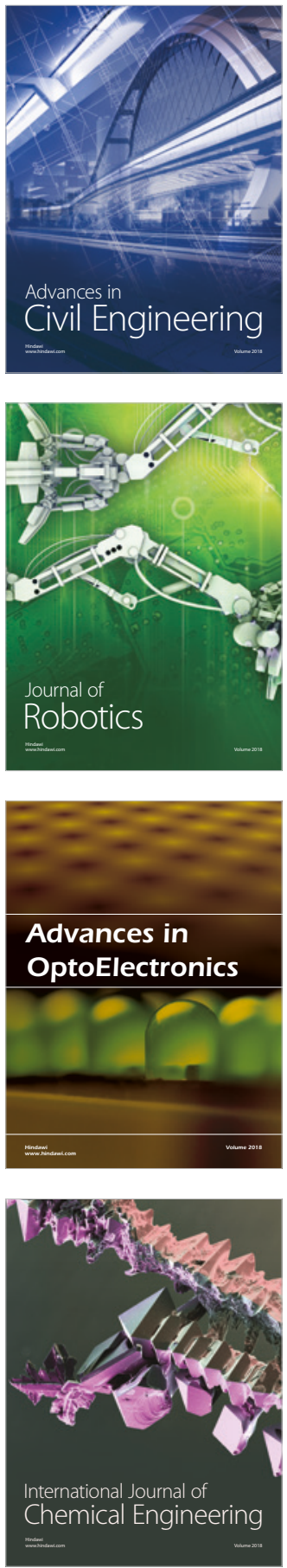

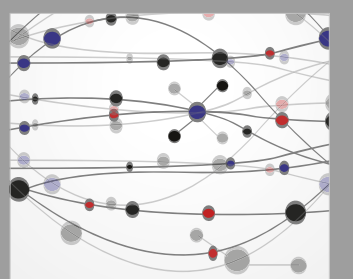

\section{Rotating \\ Machinery}

The Scientific World Journal

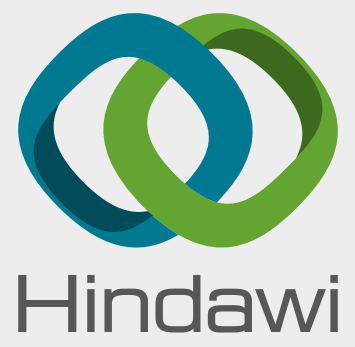

Submit your manuscripts at

www.hindawi.com
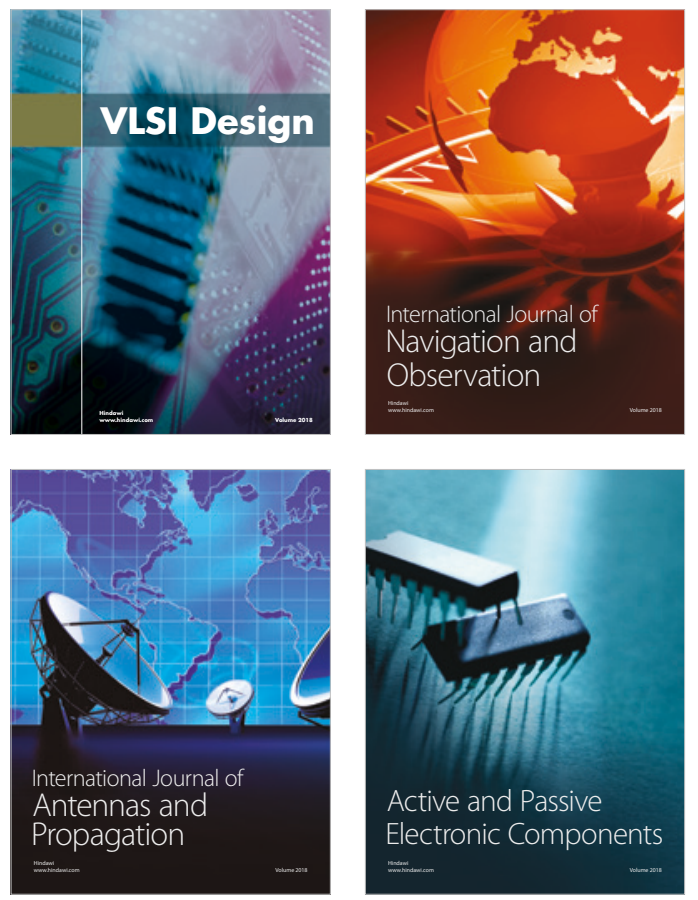
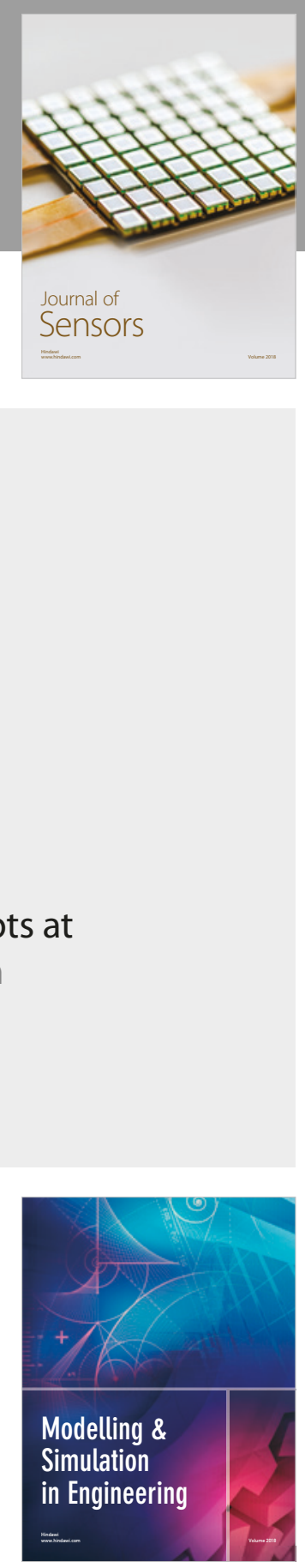

\section{Advances \\ Multimedia}
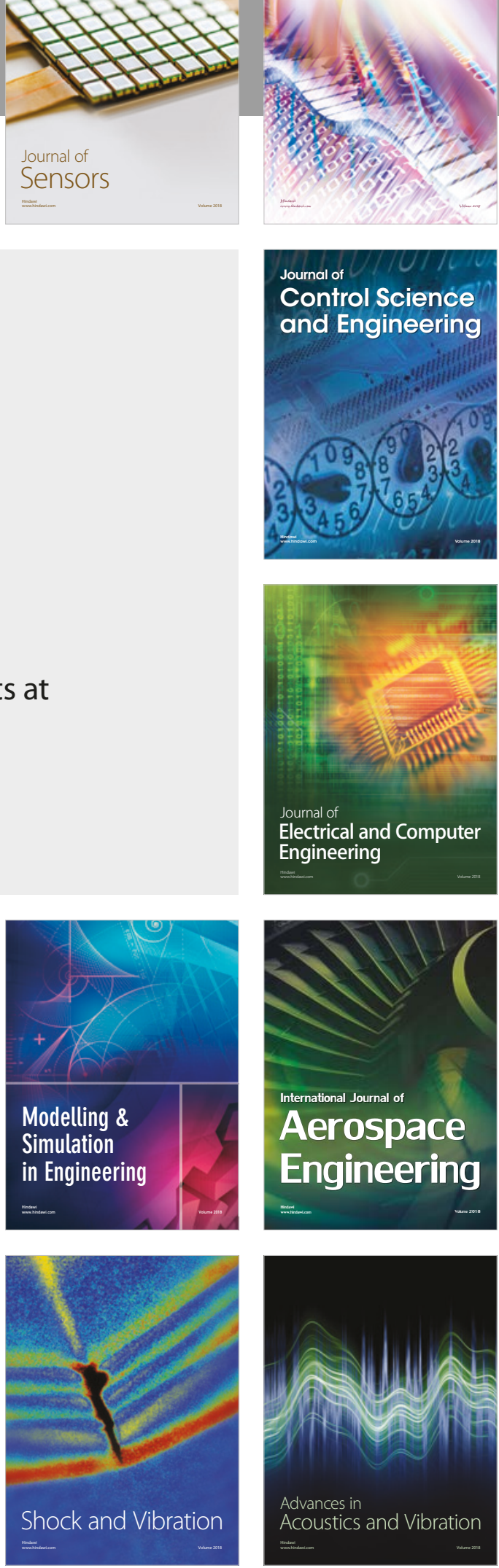